\title{
Prognostic Impact of the Neoadjuvant Rectal Score as Compared With the Tumor Regression Grade and Yield Pathologic TNM Stage in Patients With Locally Advanced Rectal Cancer After Neoadjuvant Chemoradiotherapy
}

\author{
JIN HO BAEK ${ }^{1 *}$, DONG WON BAEK ${ }^{1 *}$, BYUNG WOOG KANG ${ }^{1}$, HYE JIN KIM ${ }^{2}$, \\ SU YEON PARK ${ }^{2}$, JUN SEOK PARK ${ }^{2}$, GYU SEOG CHOI $^{2}$ and JONG GWANG KIM ${ }^{1}$ \\ ${ }^{1}$ Department of Oncology/Hematology, Kyungpook National University Chilgok Hospital, \\ School of Medicine, Kyungpook National University, \\ Kyungpook National University Cancer Research Institute, Daegu, Republic of Korea; \\ ${ }^{2}$ Department of Surgery, Kyungpook National University Chilgok Hospital, \\ School of Medicine, Kyungpook National University, Daegu, Republic of Korea
}

\begin{abstract}
Background/Aim: The present study compared the prognostic value of the yield pathologic (yp) stage, tumor regression grade (TRG), and neoadjuvant rectal (NAR) score in patients with locally advanced rectal cancer (LARC) who received neoadjuvant chemoradiotherapy $(n C R T)$. Patients and Methods: For the assessment of tumor regression, the Dworak grading system was used. The NAR score was calculated using the following equation: $(5 y p N-3[c T-y p T]+12)^{2} \div 9.61$. Results: In univariate analysis, the NAR score and ypTNM stage were significantly associated with DFS [hazard ratio $(H R)=2.514, p<0.001$ and $H R=3.200, p<0.001]$ and $O S$ $(H R=2.292, p=0.001$ and $H R=2.859, p<0.001)$, whereas the TRG was significantly associated with only DFS ( $H R=2.008, p=0.017)$. In multivariate analysis, the ypTNM stage was the only independent prognostic factor for DFS $(H R=3.796, p<0.001)$ and $O S(H R=3.591, p=0.0034)$. Conclusion: Only the ypTNM stage was significantly associated with survival outcomes in multivariate analysis,
\end{abstract}

This article is freely accessible online.

*These Authors contributed equally to this work.

Correspondence to: Jong Gwang Kim, MD, Ph.D., Department of Oncology/Hematology, Kyungpook National University Chilgok Hospital, School of Medicine, Kyungpook National University, Kyungpook National University Cancer Research Institute, 807 Hogukno, Buk-gu, Daegu 41404, Republic of Korea. Tel: +82 532002623, Fax: +82 532002029, e-mail: jkk21c@knu.ac.kr

Key Words: Rectal neoplasms, neoadjuvant therapy, neoplasm staging, prognosis. suggesting that it is the most powerful prognostic factor of $n C R T$ in patients with LARC.

Neoadjuvant chemoradiotherapy (nCRT) followed by total mesorectal excision (TME) has become the standard treatment for patients with locally advanced rectal cancer (LARC) (1). Nevertheless, LARC patients exhibit heterogeneity in responses to nCRT, and only about $15 \%-20 \%$ of patients might achieve a pathologic complete response (pCR) (2). To improve clinical outcomes, adjuvant chemotherapy is generally recommended for patients with pathologic stage II/III rectal cancer following nCRT and resection (3). However, it is important to identify patients at high risk of disease progression prior to postoperative therapy, as adjuvant chemotherapy involving fluoropyrimidine and oxaliplatin can cause severe adverse events in $30 \%-40 \%$ of patients (4).

Previous studies have suggested that pathologically determined responses to neoadjuvant treatment correlated with long-term outcomes, and thus, yield pathologic (yp) stage and tumor regression grade (TRG) have been evaluated widely to predict the prognosis of patients with LARC (5-7). Recently, neoadjuvant rectal (NAR) score was presented as an independent prognostic factor for patients who received nCRT. The NAR score is calculated according to data supported by the Valentini nomogram for overall survival (OS), using the clinical $\mathrm{T}(\mathrm{cT})$ stage and pathologic $\mathrm{T}(\mathrm{pT})$ and $\mathrm{N}(\mathrm{pN})$ stages $(8,9)$. Importantly, this score is designed to be sensitive to the changes in factors that are affected by neoadjuvant therapy, and has been validated in international clinical trials to provide evidence of clinical utility (9). In the NSABP R-04 clinical trial, which involved 1479 patients with stage II/III rectal cancer who underwent nCRT, the 
continuous NAR score was significantly associated with OS. In particular, patients with a low NAR score were reported to show a better 5-year OS (10). Moreover, the NAR score outperformed $\mathrm{pCR}$ in predicting $\mathrm{OS}$ in a retrospective study with 1,172 LARC patients. However, few studies have compared the prognostic power of the NAR score with ypStage and TRG (11).

Accordingly, the present study assessed the prognostic value of the NAR score in patients with LARC who received nCRT followed by curative surgical resection by performing comparisons with the ypStage and TRG. In addition, we attempted to identify the predictive factors that could potentially influence the response to neoadjuvant therapy.

\section{Patients and Methods}

Patients and treatment. This study retrospectively reviewed the data of 284 patients diagnosed with LARC who underwent neoadjuvant CRT followed by surgical excision at Kyungpook National University Chilgok Hospital (KNUCH) between January 2006 and October 2015. The patients were enrolled according to the following criteria: pathological diagnosis of primary rectal cancer; clinical stage II or III rectal cancer classified by the American Joint Committee on Cancer Staging (7th edition) (12); and treatment with nCRT followed by surgical excision.

The nCRT consisted of 45-50.4 Gy delivered in 25 daily fractions over 5 weeks with concurrent infusion of 5 -fluorouracil (400 $\left.\mathrm{mg} / \mathrm{m}^{2}\right)$ and leucovorin $\left(20 \mathrm{mg} / \mathrm{m}^{2}\right)$ on days 1-4 and 29-32 or oral capecitabine $\left(825 \mathrm{mg} / \mathrm{m}^{2}\right)$ twice daily, 5 days per week for 5 weeks. The TME was performed 6-8 weeks after the completion of nCRT.

Assessment of the TRG and NAR score. All surgically resected specimens were examined by pathologists at KNUCH. The pathologic reports included details on ypT stage, ypN stage, lymphovascular invasion, and perineural invasion. For assessment of the TRG, the following Dworak grading system was used: Dworak regression Grade 0 (TRG 0), no regression; Grade 1 (TRG 1), dominant tumor mass with obvious fibrosis and/or vasculopathy; Grade 2 (TRG 2), dominant fibrotic changes with few tumor cells or groups (easy to find); Grade 3 (TRG 3), very few tumor cells in fibrotic tissue with or without mucous substances (difficult to find microscopically); and Grade 4 (TRG 4), no tumor cells (only fibrotic mass) (13). The NAR score was developed according to Valentini's nomograms for OS, incorporating a weighted combination of the preCRT cT stage, post-CRT ypT stage, and ypN stage, and calculated using the following equation: $(5 \mathrm{ypN}-3[\mathrm{cT}-\mathrm{ypT}]+12)^{2} \div 9.61$ (14). The NAR score was classified as low (NAR <14.98) and high $(\mathrm{NAR} \geq 14.98)$ according to the median value (14.98).

Ethical approval. All procedures performed in studies involving human participants were in accordance with the ethical standards of the institutional and/or national research committee and with the 1964 Declaration of Helsinki and its later amendments or comparable ethical standards.

Statistical analysis. Descriptive statistics are reported as incidences and proportions. Associations between categorical variables were evaluated using the chi-squared test. Disease-free survival (DFS)
Table I. Patient and tumor characteristics.

\begin{tabular}{|c|c|c|c|c|}
\hline \multirow[t]{2}{*}{ Characteristics } & \multirow{2}{*}{$\begin{array}{c}\text { Total } \\
(n=284)\end{array}$} & \multicolumn{2}{|c|}{ NAR score } & \multirow[b]{2}{*}{$p$-Value } \\
\hline & & $\begin{array}{c}\text { Low } \\
(\mathrm{n}=105, \\
36.9 \%)\end{array}$ & $\begin{array}{c}\text { High } \\
(\mathrm{n}=179, \\
63.1 \%)\end{array}$ & \\
\hline \multicolumn{5}{|l|}{ Age } \\
\hline Median (range) & $59(25-88)$ & $58(35-85)$ & $59(25-88)$ & 0.998 \\
\hline \multicolumn{5}{|l|}{ Gender, n (\%) } \\
\hline Male & $198(69.7 \%)$ & $73(69.5 \%)$ & $125(69.8 \%)$ & 0.884 \\
\hline Female & $86(30.3 \%)$ & $32(30.5 \%)$ & $54(30.2 \%)$ & \\
\hline \multicolumn{5}{|l|}{$\begin{array}{l}\text { Clinical T stage, } \\
\mathrm{n}(\%)\end{array}$} \\
\hline cT2 & $15(5.3 \%)$ & $4(3.8 \%)$ & $11(6.1 \%)$ & 0.033 \\
\hline cT3 & $228(80.3 \%)$ & $78(74.3 \%)$ & $150(83.8 \%)$ & \\
\hline $\mathrm{cT} 4$ & $41(14.4 \%)$ & $23(21.9 \%)$ & $18(10.1 \%)$ & \\
\hline \multicolumn{5}{|l|}{$\begin{array}{l}\text { Clinical N stage, } \\
\mathrm{n}(\%)\end{array}$} \\
\hline $\mathrm{cNO}$ & $44(15.5 \%)$ & $25(23.8 \%)$ & $19(10.6 \%)$ & $<0.001$ \\
\hline $\mathrm{cN} 1$ & $95(33.5 \%)$ & $38(36.2 \%)$ & $57(31.8 \%)$ & \\
\hline $\mathrm{cN} 2$ & $145(51.1 \%)$ & $42(40.0 \%)$ & $103(57.5 \%)$ & \\
\hline \multicolumn{5}{|l|}{$\begin{array}{l}\text { Clinical stage, } \\
\mathrm{n}(\%)\end{array}$} \\
\hline Stage II & $44(15.5 \%)$ & $25(23.8 \%)$ & $19(10.6 \%)$ & 0.016 \\
\hline Stage III & $240(84.5 \%)$ & $80(76.2 \%)$ & $160(89.4 \%)$ & \\
\hline \multicolumn{5}{|c|}{$\begin{array}{l}\text { Pathologic } \mathrm{T} \text { stage, } \\
\mathrm{n}(\%)\end{array}$} \\
\hline урТ0 & $40(14.1 \%)$ & $40(38.1 \%)$ & 0 & $<0.001$ \\
\hline ypT1 & $8(2.8 \%)$ & $8(7.6 \%)$ & 0 & \\
\hline ypT2 & $51(18.0 \%)$ & $40(38.1 \%)$ & $11(6.1 \%)$ & \\
\hline урT3 & $172(60.6 \%)$ & $17(16.2 \%)$ & $155(86.6 \%)$ & \\
\hline ypT4 & $13(4.6 \%)$ & 0 & $13(7.3 \%)$ & \\
\hline \multicolumn{5}{|l|}{$\begin{array}{l}\text { Pathologic N stage, } \\
\mathrm{n}(\%)\end{array}$} \\
\hline ypN0 & $195(68.7 \%)$ & $102(97.1 \%)$ & $93(52.0 \%)$ & $<0.001$ \\
\hline ypN1 & $62(21.8 \%)$ & $3(2.9 \%)$ & $59(33.0 \%)$ & \\
\hline ypN2 & $27(9.5 \%)$ & 0 & $27(15.0 \%)$ & \\
\hline \multicolumn{5}{|l|}{$\begin{array}{l}\text { Pathologic M stage, } \\
\text { n }(\%)\end{array}$} \\
\hline урМ0 & $277(97.5 \%)$ & $103(98.1 \%)$ & $174(97.2 \%)$ & 0.538 \\
\hline ypM1 & $7(2.5 \%)$ & $2(1.9 \%)$ & $5(2.8 \%)$ & \\
\hline \multicolumn{5}{|l|}{$\begin{array}{l}\text { Pathologic Stage, } \\
\mathrm{n}(\%)\end{array}$} \\
\hline ypStage $0(\mathrm{pCR})$ & $39(13.7 \%)$ & $39(37.1 \%)$ & 0 & $<0.001$ \\
\hline ypStage I & $51(18.0 \%)$ & $47(44.8 \%)$ & $4(2.2 \%)$ & \\
\hline ypStage II & $102(35.9 \%)$ & $16(15.2 \%)$ & $86(48.0 \%)$ & \\
\hline ypStage III & $85(29.9 \%)$ & $2(1.9 \%)$ & $83(46.4 \%)$ & \\
\hline ypStage IV & $7(2.5 \%)$ & $1(1.0 \%)$ & $6(3.4 \%)$ & \\
\hline TRG, n (\%) & $\mathrm{n}=147$ & $\mathrm{n}=72$ & $\mathrm{n}=75$ & \\
\hline TRG 4 & $40(27.2 \%)$ & $40(55.6 \%)$ & 0 & $<0.001$ \\
\hline TRG 3 & $49(33.3 \%)$ & $15(20.8 \%)$ & $34(45.3 \%)$ & \\
\hline TRG 2 & $29(19.7 \%)$ & $9(12.5 \%)$ & $20(26.7 \%)$ & \\
\hline TRG 1 & $24(16.3 \%)$ & $7(9.7 \%)$ & $17(22.7 \%)$ & \\
\hline TRG 0 & $5(3.4 \%)$ & $1(1.4 \%)$ & $4(5.3 \%)$ & \\
\hline \multicolumn{5}{|l|}{ Recurrence, n (\%) } \\
\hline No & $189(66.5 \%)$ & $86(81.9 \%)$ & $103(57.5 \%)$ & 0.021 \\
\hline Yes & $95(33.5 \%)$ & $19(18.1 \%)$ & $76(42.5 \%)$ & \\
\hline \multicolumn{5}{|l|}{ Death, n (\%) } \\
\hline No & $195(68.7 \%)$ & $86(81.9 \%)$ & $109(60.9 \%)$ & 0.039 \\
\hline Yes & $89(31.3 \%)$ & $19(18.1 \%)$ & $70(39.1 \%)$ & \\
\hline
\end{tabular}

TRG: Tumor regression grade; NAR score: neoadjuvant rectal score; pCR: pathologic complete response. 

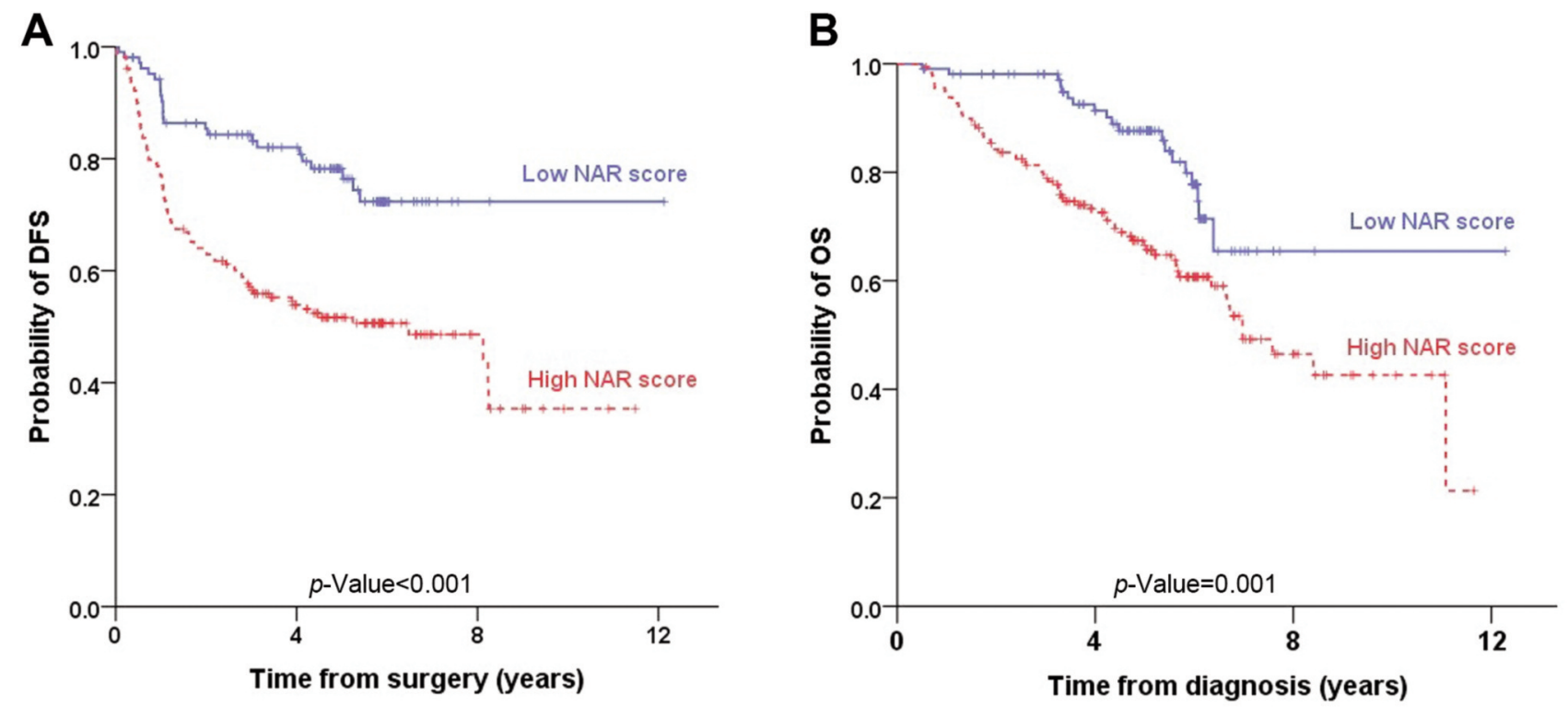

Figure 1. Kaplan-Meier curves for long-term survival outcomes. Patients with a low neoadjuvant rectal (NAR) score showed superior (A) diseasefree survival (DFS) and (B) overall survival (OS) as compared to those with a high NAR score.

was calculated from the date of surgery to the date of tumor recurrence or death from any cause. OS was calculated from the date of diagnosis to death from any cause. In event-free subjects, data were censored at the last follow-up. Survival curves were calculated using the Kaplan-Meier method and compared using the log-rank test. Multivariate analysis of prognostic factors was carried out using a Cox proportional hazard regression model. The hazard ratio (HR) and 95\% confidence interval (CI) were estimated for each factor. A $p$-value $<0.05$ was considered statistically significant. The statistical analyses were performed using SPSS for Windows (version 20.0; SPSS Inc., Chicago, IL, USA).

\section{Results}

Patient and tumor characteristics. The median patient age was 59 (range $=25-88$ ) years at the time of diagnosis, and the male-to-female ratio was $2.3: 1$. The clinical TNM stages before nCRT were II and III in $44(15.5 \%)$ and $240(84.5 \%)$ patients, respectively. The predominant histology was moderately differentiated adenocarcinoma. The pathologic stages after nCRT were as follows: ypStage 0, $\mathrm{n}=39$ (13.7\%); ypStage I, n=51 (18.0\%); ypStage II, n=102 (35.9\%); ypStage III, $\mathrm{n}=85$ (29.9\%); and ypStage IV, $\mathrm{n}=7$ (2.5\%). The Dworak grading system was applied to the 147 patients to evaluate the TRG after nCRT, and the results were as follows: TRG 4, $\mathrm{n}=40(27.2 \%)$; TRG 3, n=49 (33.3\%); TRG 2, n=29 (19.7\%); TRG 1, n=24 (16.3\%); and TRG 0, n=5 (3.4\%) (Table I).

The relevance of the NAR score with regard to clinicopathologic factors. According to the median NAR score, $179(63.1 \%)$ patients were classified in the high NAR score group and $105(36.9 \%)$ were classified in the low NAR score group. A high NAR score was significantly associated with a more advanced $\mathrm{cN}$ stage $(p<0.001)$, clinical stage $(p=0.016)$, pT stage $(p<0.001), \mathrm{pN}$ stage $(p<0.001)$, ypStage $(p<0.001)$, and TRG $(p<0.001)$. In particular, $39(37.1 \%)$ patients achieved pCR in the low NAR score group. However, patients with a high NAR score failed to achieve pCR and showed higher probability of more advanced pathologic stages. Patients with a high NAR score tended to experience more often disease recurrence and death as compared to patients with a low NAR score (Table I).

Clinical outcomes and the prognostic role of the NAR score. With a median follow-up duration of 60.3 months (range=5.0-151.0 months), local or distant recurrence occurred in 95 patients $(33.5 \%)$, and 89 patients $(31.3 \%)$ died during the follow-up period. The 5-year DFS and OS rates were $61.3 \%$ and $74.7 \%$, respectively. In the subgroup analyses, patients with a low NAR score showed superior long-term survival outcomes in terms of DFS and OS (Figure 1). The 5-year DFS and OS rates were $81.4 \%$ and $85.8 \%$, respectively, in patients with a low NAR score and $56.4 \%$ and $67.4 \%$, respectively, in patients with a high NAR score.

Independent prognostic factors affecting long-term outcomes and prognostic value comparison of the NAR score, TRG, and ypStage. In the univariate survival analysis, the NAR score (NAR score <14.98vs. $\geq 14.98$ ) and ypTNM stage 
Table II. Univariate and multivariate analyses of disease-free survival.

\begin{tabular}{|c|c|c|c|c|c|c|}
\hline \multirow[t]{3}{*}{ Variables } & \multicolumn{6}{|c|}{ Disease-free survival } \\
\hline & \multicolumn{3}{|c|}{ Univariate analysis } & \multicolumn{3}{|c|}{ Multivariate analysis } \\
\hline & HR & $95 \% \mathrm{CI}$ & $p$-Value & HR & $95 \% \mathrm{CI}$ & $p$-Value \\
\hline Age $<59 v s . \geq 59$ & 1.212 & $0.835-1.760$ & 0.311 & 0.481 & $0.220-1.050$ & 0.066 \\
\hline Male $v s$. Female & 1.017 & $0.680-1.520$ & 0.936 & 0.816 & $0.543-1.226$ & 0.328 \\
\hline ypStage 0-I vs. ypStage II-IV & 3.200 & $1.908-5.367$ & $<0.001$ & 5.223 & $1.332-20.474$ & 0.018 \\
\hline TRG 4-3 vs. TRG 2-0 & 2.008 & $1.132-3.564$ & 0.017 & 1.265 & $0.596-2.684$ & 0.540 \\
\hline NAR score $<14.98 v s . \geq 14.98$ & 2.514 & $1.600-3.951$ & $<0.001$ & 0.639 & $0.192-2.131$ & 0.466 \\
\hline Initial CEA $<5 \mathrm{ng} / \mathrm{ml} v s . \geq 5 \mathrm{ng} / \mathrm{ml}$ & 1.137 & $0.767-1.687$ & 0.522 & 0.840 & $0.386-1.828$ & 0.661 \\
\hline
\end{tabular}

CEA: Carcinoembryonic antigen; CI: confidence interval; HR: hazard ratio; NAR score: neoadjuvant rectal score; TRG: tumor regression grade; ypStage: post-neoadjuvant treatment stage.

Table III. Univariate and multivariate analyses of overall survival.

\begin{tabular}{|c|c|c|c|c|c|c|}
\hline \multirow[t]{3}{*}{ Variables } & \multicolumn{6}{|c|}{ Overall survival } \\
\hline & \multicolumn{3}{|c|}{ Univariate analysis } & \multicolumn{3}{|c|}{ Multivariate analysis } \\
\hline & HR & $95 \% \mathrm{CI}$ & $p$-Value & HR & $95 \% \mathrm{CI}$ & $p$-Value \\
\hline Age $<59$ vs. $\geq 59$ & 1.442 & $0.941-2.209$ & 0.093 & 2.065 & $0.957-4.453$ & 0.064 \\
\hline Male $v s$. Female & 0.969 & $0.614-1.531$ & 0.894 & 0.701 & $0.312-1.572$ & 0.388 \\
\hline ypStage 0-I vs. ypStage II-IV & 2.859 & $1.613-5.067$ & $<0.001$ & 3.591 & $1.536-8.394$ & 0.003 \\
\hline TRG 4-3 vs. TRG 2-0 & 1.689 & $0.834-3.420$ & 0.145 & 1.223 & $0.586-2.552$ & 0.592 \\
\hline NAR score $<14.98 v s . \geq 14.98$ & 2.292 & $1.378-3.814$ & 0.001 & 0.656 & $0.198-2.174$ & 0.490 \\
\hline Initial CEA $<5 \mathrm{ng} / \mathrm{ml} v s . \geq 5 \mathrm{ng} / \mathrm{ml}$ & 1.393 & $0.903-2.147$ & 0.134 & 0.840 & $0.386-1.828$ & 0.661 \\
\hline
\end{tabular}

CEA: Carcinoembryonic antigen; CI: confidence interval; HR: hazard ratio; NAR score: neoadjuvant rectal score; TRG: tumor regression grade; ypStage: post-neoadjuvant treatment stage.

(ypStage 0-I vs. ypStage II-IV) were significantly associated with DFS $(\mathrm{HR}=2.514,95 \% \mathrm{CI}=1.600-3.951, p<0.001$ and $\mathrm{HR}=3.200,95 \% \mathrm{CI}=1.908-5.367, p<0.001$, respectively) and OS $\quad(\mathrm{HR}=2.292, \quad 95 \% \mathrm{CI}=1.378-3.814, \quad p=0.001 \quad$ and $\mathrm{HR}=2.859,95 \% \mathrm{CI}=1.613-5.067, p<0.001$, respectively), whereas the TRG category (TRG 4-3 vs. TRG 2-0) was significantly associated with DFS only (HR=2.008, 95\% CI $=1.132-3.564, p=0.017$ ) (Table II and Table III). The HR of the ypTNM stage was higher than that of the NAR score and TRG in the univariate analysis for DFS and OS. In the multivariate survival analysis, the ypTNM stage was the only independent prognostic factor for DFS $(\mathrm{HR}=2.859$, $95 \% \mathrm{CI}=1.613-5.067, \quad p<0.001)$ and $\mathrm{OS} \quad(\mathrm{HR}=2.292$, $95 \% \mathrm{CI}=1.378-3.814, p=0.001)$.

\section{Discussion}

We investigated the clinical impact of the NAR score and compared the prognostic value with the ypStage and TRG in a relatively large cohort of patients with LARC. The present study showed the potential of the NAR score to be a prognostic indicator after nCRT. However, the NAR score was not the most reliable prognostic factor when compared with the ypStage and TRG.

George et al. demonstrated that the $\mathrm{pT}$ stage and $\mathrm{pN}$ stage are potentially influenced by nCRT, and tumor downstaging is more important than the absolute pathologic stage (9). Thus, the NAR score was proposed as a clinical trial surrogate endpoint using only the cT stage, pT stage, and $\mathrm{pN}$ stage according to the Valentini nomogram for OS $(8,9)$. Although, it has already been adopted in clinical trials, such as those involving total neoadjuvant therapy and novel interventions for rectal cancer, validation and standardization for clinical use are still needed. In the NSABP R-04 trial, the NAR score was categorized as low $(\mathrm{NAR}<8)$, intermediate (NAR=8-16), and high (NAR>16), and these categories were significantly associated with OS, with 5-year OS rates of $92 \%, 89 \%$, and $68 \%$, respectively (14). In the present study, patients were classified according to a mean NAR score of 14.98. Similar to previous studies, the proportions of 
advanced cT stage, pT stage, and pN stage were higher in patients with high NAR scores, which were correlated with recurrence rate and death.

Recent data showed that the NAR score had greater predictive value than $\mathrm{pCR}$, and it could help in predicting DFS in LARC patients after nCRT (15). Nevertheless, the NAR score alone may not be the most suitable prognostic factor for LARC. Previous studies have reported that the Dworak TRG system and pathologic TNM staging are independent prognostic factors for recurrence and survival in patients with LARC treated with nCRT followed by surgery (16-19). Song et al. demonstrated that the prognostic value of the TRG remained significant, even after adjusting for other well-established prognostic factors, such as the ypN stage, in multivariate analysis (20). In addition, patients with pCR and those with good tumor regression, even in the absence of pCR, have been reported to have good outcomes $(18,19,21,22)$. Meanwhile, Quah et al. reported that the ypStage was more strongly associated with DFS than the TRG in 342 patients with rectal cancer who received nCRT (23). In accordance with previous studies, our data showed that the ypStage, TRG, and NAR score were associated with DFS and the ypStage and NAR score were associated with OS in univariate survival analysis. However, the HR of the ypStage was higher than the values of the TRG and NAR score. Furthermore, in the multivariate survival analysis, including these 3 prognostic factors, only the ypStage was significantly associated with DFS and OS, suggesting that the ypStage is the most influential prognostic factor in patients with LARC after nCRT.

Some previous studies have evaluated the effect of adjuvant chemotherapy following nCRT and surgery in patients with LARC. Although a meta-analysis of four randomized trials demonstrated that adjuvant fluorouracilbased chemotherapy did not improve DFS and OS (15), more recent studies showed that adjuvant chemotherapy improved long-term survival outcomes and that adding oxaliplatin to fluorouracil-based regimens significantly improved DFS in patients with LARC $(24,25)$. However, its role is not well-defined yet, and there is no consensus on the precise indication of adjuvant chemotherapy. In a study of 245 LARC patients, the 5-year DFS and OS rates were 96\% and $100 \%$, respectively, in patients who achieved pCR and were only followed up without additional adjuvant chemotherapy (26). In addition, according to results from the NCCN colorectal cancer database, achieving pCR was associated with not receiving adjuvant chemotherapy (27). Our results showed that patients with a high NAR score tended to have a more advanced pathologic stage and that the proportions of recurrence and death were higher in these patients than in those with a low NAR score. Therefore, poor prognosis is predicted in LARC patients with a high NAR score, which might lead these patients to be classified as a high-risk group, which might be helpful in the decision regarding whether or not to recommend adjuvant chemotherapy in an individual patient. However, since the ypTNM was the most important prognostic factor in the multivariate analysis, oxaliplatin plus fluorouracil-based adjuvant chemotherapy could be recommended after nCTR and surgery according to the ypStage.

In conclusion, only the ypTNM stage was significantly associated with survival outcomes in the multivariate analysis, suggesting that it is the most powerful prognostic factor of nCRT in patients with LARC. Well-designed multicenter studies are still needed to validate the prognostic significance of the NAR score in order to make better strategies after nCRT and improve long-term clinical outcomes in patients with LARC.

\section{Conflicts of Interest}

The Authors declare that they have no conflicts of interest regarding this study.

\section{Authors' Contributions}

J.G.K designed the study; J.H.B, D.W.B, B.W.K, H.J.K, S.Y.P, J.S.P and G.S.C collected the data; J.H.B, D.W.B and J.G.K analyzed and interpreted the data; J.H.B and D.W.B wrote the paper; J.G.K contributed to the review and revision of the manuscript.

\section{Acknowledgements}

This work was supported by the National Research Foundation of Korea (NRF) grant funded by the Korea government (2014R1A5A2009242)

\section{References}

1 Sauer R, Becker H, Hohenberger W, Rodel C, Wittekind C, Fietkau R, Martus P, Tschmelitsch J, Hager E, Hess CF, Karstens JH, Liersch T, Schmidberger H, Raab R and German Rectal Cancer Study Group: Preoperative versus postoperative chemoradiotherapy for rectal cancer. N Engl J Med 351: 17311740, 2004. PMID: 15496622. DOI: 10.1056/NEJMoa040694

2 De Caluwe L, Van Nieuwenhove $\mathrm{Y}$ and Ceelen WP: Preoperative chemoradiation versus radiation alone for stage II and III resectable rectal cancer. Cochrane Database Syst Rev (2): CD006041, 2013. PMID: 23450565. DOI: 10.1002/14651858. CD006041.pub3

3 Bujko K, Glimelius B, Valentini V, Michalski W and Spalek M: Postoperative chemotherapy in patients with rectal cancer receiving preoperative radio(chemo)therapy: A meta-analysis of randomized trials comparing surgery $+/$-a fluoropyrimidine and surgery+a fluoropyrimidine+/-oxaliplatin. Eur J Surg Oncol 41: 713-723, 2015. PMID: 25911110. DOI: 10.1016/j.ejso. 2015.03.233

4 Kahn KL, Adams JL, Weeks JC, Chrischilles EA, Schrag D, Ayanian JZ, Kiefe CI, Ganz PA, Bhoopalam N, Potosky AL, Harrington DP and Fletcher RH: Adjuvant chemotherapy use and 
adverse events among older patients with stage III colon cancer. JAMA 303: 1037-1045, 2010. PMID: 20233821. DOI: 10.1001/ jama.2010.272

5 Omejc M and Potisek M: Prognostic significance of tumor regression in locally advanced rectal cancer after preoperative radiochemotherapy. Radiol Oncol 52: 30-35, 2018. PMID: 29520203. DOI: 10.1515/raon-2017-0059

6 Lee SY, Jo JS, Kim HJ, Kim CH, Kim YJ and Kim HR: Prognostic factors for low rectal cancer patients undergoing intersphincteric resection after neoadjuvant chemoradiation. J Surg Oncol 111: 1054-1058, 2015. PMID: 25977149. DOI: $10.1002 /$ jso .23932

7 Chetty R, Gill P, Bateman AC, Driman DK, Govender D, Bateman AR, Chua YJ, Greywoode G, Hemmings C, Imat I, Jaynes E, Lee CS, Locketz M, Rowsell C, Rullier A, Serra S, Szentgyorgyi E, Vajpeyi R, Delaney D and Wang LM: Pathological grading of regression: an International Study Group perspective. J Clin Pathol 65: 865-866, 2012. PMID: 22859397. DOI: $10.1136 /$ jclinpath-2012-201054

8 Valentini V, van Stiphout RG, Lammering G, Gambacorta MA, Barba MC, Bebenek M, Bonnetain F, Bosset JF, Bujko K, Cionini L, Gerard JP, Rodel C, Sainato A, Sauer R, Minsky BD, Collette L and Lambin P: Nomograms for predicting local recurrence, distant metastases, and overall survival for patients with locally advanced rectal cancer on the basis of European randomized clinical trials. J Clin Oncol 29: 3163-3172, 2011. PMID: 21747092. DOI: 10.1200/JCO.2010.33.1595

9 George TJ, Jr., Allegra CJ and Yothers G: Neoadjuvant rectal (NAR) score: A new surrogate endpoint in rectal cancer clinical trials. Curr Colorectal Cancer Rep 11: 275-280, 2015. PMID: 26321890. DOI: $10.1007 / \mathrm{s} 11888-015-0285-2$

10 Roy A, Olsen JR, Myerson RJ, Markovina S, DeWees TA and Parikh PJ: Short-term endpoints for neoadjuvant rectal cancer therapy: Pathologic complete response or neoadjuvant rectal cancer score? Int Radiat Oncol Biol Phys 96(2S): abstr 2492, 2016. DOI: $10.1016 /$ j.ijrobp.2016.06.1096

11 Raissouni S, Mercer J, Gresham G, Kumar A, Goodwin RA, Jiang M, Leung A, Heng D, Tang PA, Doll CM, MacLean A, Powell ED, Hiller JP, Monzon JG, Cheung WJ and Vickers MM: External validation of the neoadjuvant rectal (NAR) score and Valentini prediction nomogram (VPN): a multicenter study. J Clin Oncol 32(15_suppl): 3532, 2014. DOI: 10.1200/jco.2014.32.15_suppl.3532

12 Edge SB and Compton CC: The American Joint Committee on Cancer: the 7th edition of the AJCC cancer staging manual and the future of TNM. Ann Surg Oncol 17: 1471-1474, 2010. PMID: 20180029. DOI: 10.1245/s10434-010-0985-4

13 Dworak O, Keilholz L and Hoffmann A: Pathological features of rectal cancer after preoperative radiochemotherapy. Int J Colorectal Dis 12: 19-23, 1997. PMID: 9112145. DOI: 10.1007/ s003840050072

14 O'Connell MJ, Colangelo LH, Beart RW, Petrelli NJ, Allegra CJ, Sharif S, Pitot HC, Shields AF, Landry JC, Ryan DP, Parda DS, Mohiuddin M, Arora A, Evans LS, Bahary N, Soori GS, Eakle J, Robertson JM, Moore DF, Jr., Mullane MR, Marchello BT, Ward PJ, Wozniak TF, Roh MS, Yothers G and Wolmark N: Capecitabine and oxaliplatin in the preoperative multimodality treatment of rectal cancer: surgical end points from National Surgical Adjuvant Breast and Bowel Project trial R-04. J Clin Oncol 32: 1927-1934, 2014. PMID: 24799484. DOI: 10.1200/ JCO.2013.53.7753
15 Breugom AJ, Swets M, Bosset JF, Collette L, Sainato A, Cionini L, Glynne-Jones R, Counsell N, Bastiaannet E, van den Broek $\mathrm{CB}$, Liefers GJ, Putter $\mathrm{H}$ and van de Velde CJ: Adjuvant chemotherapy after preoperative (chemo)radiotherapy and surgery for patients with rectal cancer: a systematic review and metaanalysis of individual patient data. Lancet Oncol 16: 200-207, 2015. PMID: 25589192. DOI: 10.1016/S1470-2045(14)71199-4

16 Maas M, Nelemans PJ, Valentini V, Das P, Rodel C, Kuo LJ, Calvo FA, Garcia-Aguilar J, Glynne-Jones R, Haustermans K, Mohiuddin M, Pucciarelli S, Small W, Jr., Suarez J, Theodoropoulos G, Biondo S, Beets-Tan RG, Beets GL: Longterm outcome in patients with a pathological complete response after chemoradiation for rectal cancer: a pooled analysis of individual patient data. Lancet Oncol 11: 835-844, 2010. PMID: 20692872. DOI: 10.1016/S1470-2045(10)70172-8

17 Guillem JG, Chessin DB, Cohen AM, Shia J, Mazumdar M, Enker W, Paty PB, Weiser MR, Klimstra D, Saltz L, Minsky BD and Wong WD: Long-term oncologic outcome following preoperative combined modality therapy and total mesorectal excision of locally advanced rectal cancer. Ann Surg 241: 829836, 2005; discussion 836-828. PMID: 15849519. DOI: 10.1097/01.sla.0000161980.46459.96

18 Fokas E, Liersch T, Fietkau R, Hohenberger W, Beissbarth T, Hess C, Becker H, Ghadimi M, Mrak K, Merkel S, Raab HR, Sauer R, Wittekind C and Rodel C: Tumor regression grading after preoperative chemoradiotherapy for locally advanced rectal carcinoma revisited: updated results of the CAO/ARO/AIO-94 trial. J Clin Oncol 32: 1554-1562, 2014. PMID: 24752056. DOI: 10.1200/JCO.2013.54.3769

19 Kuo LJ, Liu MC, Jian JJ, Horng CF, Cheng TI, Chen CM, Fang WT and Chung YL: Is final TNM staging a predictor for survival in locally advanced rectal cancer after preoperative chemoradiation therapy? Ann Surg Oncol 14: 2766-2772, 2007. PMID: 17551794. DOI: 10.1245/s10434-007-9471-z

20 Song C, Chung JH, Kang SB, Kim DW, Oh HK, Lee HS, Kim JW, Lee KW, Kim JH and Kim JS: Impact of tumor regression grade as a major prognostic factor in locally advanced rectal cancer after neoadjuvant chemoradiotherapy: a proposal for a modified staging system. Cancers (Basel) 10: 319, 2018. PMID: 30205529. DOI: $10.3390 /$ cancers 10090319

21 Rodel C, Martus P, Papadoupolos T, Fuzesi L, Klimpfinger M, Fietkau R, Liersch T, Hohenberger W, Raab R, Sauer R and Wittekind C: Prognostic significance of tumor regression after preoperative chemoradiotherapy for rectal cancer. J Clin Oncol 23: 8688-8696, 2005. PMID: 16246976. DOI: $10.1200 / J C O$. 2005.02.1329

22 Agarwal A, Chang GJ, Hu CY, Taggart M, Rashid A, Park IJ, You YN, Das P, Krishnan S, Crane CH, Rodriguez-Bigas M, Skibber J, Ellis L, Eng C, Kopetz S and Maru DM: Quantified pathologic response assessed as residual tumor burden is a predictor of recurrence-free survival in patients with rectal cancer who undergo resection after neoadjuvant chemoradiotherapy. Cancer 119: 4231-4241, 2013. PMID: 24089344. DOI: $10.1002 /$ cncr.28331

23 Quah HM, Chou JF, Gonen M, Shia J, Schrag D, Saltz LB, Goodman KA, Minsky BD, Wong WD and Weiser MR: Pathologic stage is most prognostic of disease-free survival in locally advanced rectal cancer patients after preoperative chemoradiation. Cancer 113: 57-64, 2008. PMID: 18442099. DOI: $10.1002 /$ cncr.23516 
24 Rodel C, Graeven U, Fietkau R, Hohenberger W, Hothorn T, Arnold D, Hofheinz RD, Ghadimi M, Wolff HA, LangWelzenbach M, Raab HR, Wittekind C, Strobel P, Staib L, Wilhelm M, Grabenbauer GG, Hoffmanns H, Lindemann F, Schlenska-Lange A, Folprecht G, Sauer R, Liersch T and German Rectal Cancer Study Group: Oxaliplatin added to fluorouracil-based preoperative chemoradiotherapy and postoperative chemotherapy of locally advanced rectal cancer (the German CAO/ARO/AIO-04 study): final results of the multicentre, open-label, randomised, phase 3 trial. Lancet Oncol 16: 979-989, 2015. PMID: 26189067. DOI: 10.1016/S14702045(15)00159-X

25 Hong YS, Nam BH, Kim KP, Kim JE, Park SJ, Park YS, Park JO, Kim SY, Kim TY, Kim JH, Ahn JB, Lim SB, Yu CS, Kim JC, Yun SH, Kim JH, Park JH, Park HC, Jung KH and Kim TW: Oxaliplatin, fluorouracil, and leucovorin versus fluorouracil and leucovorin as adjuvant chemotherapy for locally advanced rectal cancer after preoperative chemoradiotherapy (ADORE): an open-label, multicentre, phase 2, randomised controlled trial. Lancet Oncol 15: 1245-1253, 2014. PMID: 25201358. DOI: $10.1016 /$ S1470-2045(14)70377-8
26 Tranchart H, Lefevre JH, Svrcek M, Flejou JF, Tiret E and Parc $\mathrm{Y}$ : What is the incidence of metastatic lymph node involvement after significant pathologic response of primary tumor following neoadjuvant treatment for locally advanced rectal cancer? Ann Surg Oncol 20: 1551-1559, 2013. PMID: 23188545. DOI: 10.1245/s10434-012-2773-9

27 Khrizman P, Niland JC, ter Veer A, Milne D, Bullard Dunn K, Carson WE, 3rd, Engstrom PF, Shibata S, Skibber JM, Weiser MR, Schrag D and Benson AB: Postoperative adjuvant chemotherapy use in patients with stage II/III rectal cancer treated with neoadjuvant therapy: a national comprehensive cancer network analysis. J Clin Oncol 31: 30-38, 2013. PMID: 23169502. DOI: $10.1200 / J C O .2011 .40 .3188$

Received April 6, 2020

Revised April 13, 2020

Accepted April 14, 2020 